\title{
Leprosy and the Internet
}

\author{
J. S. GILBODY \\ altra@globalnet.co.uk
}

Few things have been hyped in the media as much as the Internet, and yet its practical value remains unappreciated by most people. I therefore thought it would be useful to list some practical ways in which the Net might benefit the leprosy worker or unit.

\section{Background}

When people talk about the Internet, they usually mean the World Wide Web (the Web), a relatively recent development, but undoubtedly the most user-friendly and useful part of the Internet. The Web is basically a global, open network of many computers, any of which can be easily and quickly accessed by users anywhere in the world. The beauty of the Web is that it is based on easy-to-use 'point and click' Windows-type Web browsing software, and it is flexible, allowing text, pictures and sound to be accessed and downloaded from Web sites. As technology improves (particularly data transfer speeds), the Internet should become a fullyfledged communications network, e.g. for telephones, videophones/videoconferencing, movies, and shopping and banking transactions.

To access a given Web site, the user need only type in the site's address, which usually has the format http://www.NAME OF WEB SITE. So, for example, the US Food and Drug Administration's Web address is http://www.fda.gov. The number of Web sites worldwide is growing rapidly (in fact exponentially), and currently stands at around one million. A huge amount of information is available on any subject, limited only by the imagination (and persistence!) of the user.

\section{Equipment and cost}

To access the Internet, you will need a PC (personal computer), modem and telephone line, by which means you dial up a server. The costs incurred by you therefore comprise a telephone call (usually local rate) plus on-line time paid to your server. To reduce cost, many servers now offer a fixed monthly charge, e.g. $£ 10$, which gives unlimited access to the Internet, i.e. no on-line charges apart from that of the telephone call. Beyond these costs, there are no other charges; most Web sites are free to access, and there are no extra costs for accessing overseas Web sites. A Web site on the other side of the world is as quick and easy to access as one 10 miles away. Geography ceases to be a limiting factor, which would be of great value to leprosy workers, particularly those in isolated rural areas. Within the next 1-2 years, low-cost, high-speed global satellite links and phones should become available, 
e.g. based on the satellites of the Iridium Network, which are currently being launched, so that even a telephone 'land line' won't be needed.

\section{How to find relevant Web sites}

How can information and relevant Web sites be found quickly, without spending hours surfing the Net? Web sites are 'indexed' by search engines, which are basically Web sites devoted to exploring and indexing other Web sites. As the number of Web sites and their contained text is so huge, powerful workstation computers are of ten used for this purpose. There are many dozens of different search engines, and some Web sites specialize in allowing multiple search engines to be utilized simultaneously (such as SavvySearch). One good search engine is Yahoo (http://www.yahoo.com), which rigorously classifies all of its data, and is a good place to start, e.g. for medical dictionaries and journals, regional newspapers etc. However, it is not as thorough as other search engines, the best of which are HotBot (www.hotbot.com) and AltaVista (www.altavista.digital.com).

Whichever search engine you use, searches can typically be performed in a few seconds, and may result in many thousands of hits (Web sites containing the word(s) you are interested in). Clearly, some Web sites will be more relevant to your search from others, ranging from sites mentioning your key word(s) just once, to sites devoted solely to your subject of interest. Thankfully, good search engines will indicate the best Web sites, by such means as a star system or percentage rating. When I did such a search for leprosy on HotBot, for example, I had 7,404 hits - although not all of these sites were useful, of course! Some good leprosy Web sites are as follows:

1 The British Leprosy Relief Association (LEPRA; http://www.lepra.org.uk): 'A medical charity with the single aim of the eradication of leprosy'. Includes the contents and editorial pages of Leprosy Review.

2 World Health Organization Action Programme for the Elimination of Leprosy (http:// www.who.ch/programmes/lep/lep_home.htm): 'A world without leprosy is no longer a dream'.

3 International Federation of Anti-leprosy Associations (hhtp://www.oneworld.org/ilep/ ilep_x.htm): 'ILEP is a federation of all the main donor non-governmental agencies supporting anti-leprosy work worldwide'.

4 INFOLEP (http://infolep.twinfo.nl/infolep): 'The leprosy information services of the Netherlands Leprosy Relief Association (NSL). ... An information and documentation centre offering its services to all those who need information on leprosy in all its various aspects'.

5 The ILEP Action Group on Teaching and Learning Materials (TALMilep; http://www. oneworld.org/ilep/talmilep.htm): 'Undertakes to stimulate, facilitate and co-ordinate efforts to provide and distribute teaching materials in leprosy worldwide. Since its conception in 1983, TALMilep has produced and distributed a wide range of publications, many in multiple language editions'.

6 American Leprosy Missions (http://www.leprosy.org/): 'Celebrating 90 years of ministry to people with leprosy'.

7 International Journal of Leprosy (http://www.allenpress.com/catalogue/index/lepr/index. html). 
8 CIOMAL International Committee of the Order of Malta for Leprosy Relief (http://www. oneworld.org/ilep/ilep_x.htm).

9 Urban Leprosy Control Programme (http://www.pcsadvt.com/glra-india/urban.htm): 'The Greater Madras Leprosy Treatment and Health Education Scheme (GERMALTES) was launched by GLRA in 1971, with the objective of controlling the spread of the disease in Madras'.

10 Novartis Foundation (http://www.foundation.novartis.com/leproj.htm): 'Leprosy projects: numerous countries and projects, including active case finding, comprehensive care (MDT and deformity care), mobile clinic and social marketing, and Mother Teresa's Leprosy Centre'.

11 Leprosy Discussion List (http://www.who.ch/programmes/lep/15.htm): 'An experimental discussion list for scientists, programme managers, agencies and individuals involved and interested in the elimination of leprosy as a public health problem ... set up by the WHO Action Programme for the Elimination of Leprosy'. This list started on 26 February 1996.

12 American Leprosy Foundation (http://www.charity.org/alf.html): 'Offers training courses, workshops and seminars to scientists, leprologists, and students of infectious diseases on an international scale. The Foundation establishes and maintains clinics and hospitals for diagnosis and treatment. Because of widespread misunderstanding of leprosy, the Foundation strives to educate the public that leprosy still exists and that its victims must be helped'.

13 Flight Aid Trust (http://www.mersinet.co.uk/flight-aid/.) A group of aviation enthusiasts and pilots that helps to fund the long-term treatment and rehabilitation of victims of leprosy in Zambia.

14 Support Groups for Leprosy (http://www.jaring.my/winweb/medical/category/ med51.htm).

\section{Other potential benefits of the Internet}

E-mail: Apart from on-line charges, e-mail is free, instantaneous to anywhere in the world, and is not subject to local postal difficulties. Moreover, an e-mail sent to 100 recipients can be sent as quickly as one for a single recipient, in contrast to a fax, which would need to be sent 100 times.

'Free' telephone calls: Many computer programs now exist which allow your computer to be used like a speakerphone (provided you have a full-duplex soundcard, speakers and a microphone). It is then possible to communicate by telephone or fax with anyone else in the world having similar software and an e-mail address, all for the cost of on-line time only. This may have major cost-saving implications, particularly for international phone calls. The US company Intel (which manufactures about three-quarters of the world's computer chips) markets state-of-the-art Internet phone programs (audio and video), which can be downloaded free from its Web site (http://www.intel.com). Current developments in this area include telephones which can be plugged directly into the Internet, without the need for expensive software or computers, and programs which allow you to contact any telephone number, i.e. normal phones, from your computer.

Access to databases and medical journals: Many databases such as Medline, e.g. http:// www.medscape.com, and journals such as the Lancet (www.thelancet.com), British Medical Journal (www.bmj.com) and New England Journal of Medicine (www.nejm.org) can be 
accessed via the Internet, usually for free. In this way, the world's resources, greater than any single library, can be available to a leprosy worker or unit anywhere in the world, however remote. The other implication is that the time wastage and costs associated with travelling to libraries, subscribing to journals, or using expensive non-Internet databases can be avoided. Articles can be ordered on-line if desired, and full-text articles are increasingly put on Web sites, allowing the user to read the full article (rather than just an abstract) without even needing to order it.

Co-operation: Forums of like-minded people on any subject can easily be set up, e.g. Usenet newsgroups, if they don't already exist, which could enable leprosy workers anywhere in the world, for example, to share information and solve problems more easily. Problems posted on Web sites can also be answered by any interested 'visitors'. Recently, there was a case of a Chinese patient with a puzzling medical condition who was diagnosed by doctors browsing a Web site - the first such case of its kind. Even X-rays and CT scans can be viewed on Web sites, the only limitation being the user's imagination (together with the available technology and cost, of course!).

I hope that this article has given a hint as to how the Internet may be useful for leprosy workers and others, even if I have only scratched the surface of what is possible. Fundamentally, the Internet is as broad as the people who use it, and as the number of users inevitably grows, and technology advances, it will become increasingly heterogeneous and mainstream, e.g. incorporated within television sets and telephones; home shopping. The bottomline is that if you cannot see a current use of the Internet for you, invent one, share the information, and watch your ideas grow! 